\title{
Characterisation of heterogeneities and evaluation of properties of nuclear grade graphite
}

\author{
S. Negi $^{1}$, J. Korody ${ }^{1 *}$, I. Khan ${ }^{2}$ and D. Kanse ${ }^{2}$ \\ ${ }^{1}$ Faculty of Engineering, Manipal University Jaipur, \\ Dehmi Kalan, Off Jaipur-Ajmer Expressway, Jaipur 303 007, Rajasthan, India \\ Phone: +91 141 3999140; Fax: +91 1413999114 \\ Email: jagan.korody@jaipur.manipal.edu \\ ${ }^{2}$ RSD, BARC, Trombay, Mumbai, 400085 India.
}

\begin{abstract}
Graphite is one of the promising candidates to be used in the next-generation first breeder reactors as a moderator against first moving neutron effluence. During interaction with the neutron, substantial change in microstructure and mechanical and thermal properties occur for graphite. This affects its in-reactor performance. The changes depend on the characteristics of as received virgin material. Therefore, it is necessary to characterize asreceived graphite accurately. This paper reports the microstructural characterisation of different nuclear graphite. Four different nuclear graphites were obtained from open source through end-user and were examined in the optical microscope. Quantification of microstructural features was carried out by Analysis Five software. A considerable number of pores with cracks were seen within the matrix. The pores and crack size distribution were found in the range of $0-10 \mu \mathrm{m}^{2}$ to a $400-1000 \mu \mathrm{m}^{2}$ for the investigated samples. The majority of the pores and cracks were seen within the range of $10-100 \mu \mathrm{m}^{2}$ area. The total porosity was to the tune of $9.25-5.78 \%$. Pores and cracks of a broad variety of the size were found, and which were uniformly distributed. The theoretical density was calculated from the obtained pores and cracks percentage data. There was no correlation found between the pores and the cracks density (no of pores and cracks per $\mathrm{mm}^{2}$ ) and the theoretical density of the graphite samples. Density was found to be independent of sizes of pores and cracks of nuclear graphite.
\end{abstract}

Keywords: Nuclear grade graphite; microstructural characterization; aspect ratio; theoretical density.

\section{INTRODUCTION}

In 1942, the first graphite neutron moderator Chicago Pile 1 (CP-1) was constructed under the Manhattan Engineer Project in the United States of America [1]. Graphite is now widely employed as a moderator, reflector, fuel matrix in several cases of nuclear reactors such as gas-cooled reactor (e.g. AGR, MAGNOX), Russian RBMK reactors, high temperature gascooled reactor (Dragon, Peach Bottom, AVR, THTR-300, Fort St. Vain, HTTR, HTR-10) and so on [2]. 
Nuclear grade graphite is a synthetic type graphite. Graphite has a low neutron property, hence making it desirable for the nuclear application [3]. A unique quality in graphite is high purity, ability to withstand high temperature, good moderating and reflector efficiency. Nuclear graphite has a porous microstructure, porosity changes with thermal and radiolytic oxidation and with high neutron fluences [4-8]. Porosity affects the mechanical and thermal properties of nuclear grade graphite [9-14].

Porosity in a porous material is calculated by various conventional methods such as the use of mercury porosimeter, acoustic emission and adsorption technique [15-17], but with the advent of new advanced technologies like microstructural modelling and image processing, the microstructural characterization can be done easily [18-21]. The development of more advanced software packages, image processing, and image analysis methods can be done more efficiently. Size and shape distribution of porosity data can be easily acquired from optical, scanning electron micrographs. Microstructural characterization of nuclear grade graphite is of utmost importance as the material suffers from a significant change in thermal and mechanical properties resulting from the irradiation and oxidation induced microstructural changes. It is essential to characterize the microstructures before and after irradiation.

Previously many researchers have studied the microstructure of the nuclear graphite using optical and scanning electron images. In 2008, researchers [22] used optical and scanning electron microscopes to characterize the microstructure of baked carbon block and graphitized grades of the nuclear grade graphite. Baked carbon block showed matrix with no clear structure with a high degree of porosity. At higher magnification, graphitized grade showed highly oriented crystals with a smaller number of pores in comparison with the baked block. It was inferred that graphitization changed the microstructure. Wen [23] characterized the microstructure of the binder in two grades of graphite, gilsocarbon graphite and pile grade. A graphite using optical and transmission electron microscopes. Round pores were observed in binder phase and elongated calcination cracks in the filler particle. Quantitative analysis of the microstructure was performed by Kane [24] using image analysis of optical micrograms to study the microstructure and the pore structure of the IG-110, PGX, NBG-18, PCEA nuclear graphites. Computer-aided image analysis technique was used to quantify properties such as pore area, pore eccentricity, and total porosity. However, the pore shape was assumed to be an ellipse. However, this assumption becomes less accurate as pore size increases. Many of the smallest pores and cracks are simple enough to be well defined by an ellipse, but the pores and cracks of complex shapes cannot accurately be defined with this analysis. The information available is to some extent incomplete and contradictory. This work concentrates on the microstructural characterisation of the newly developed virgin nuclear graphite. In this investigation image analysis of the optical micrographs is carried out. The current study uses thresholding technique (Image segmentation) to identify the pores and cracks. In the thresholding process, the structures are identified in the gray-value image, based on the brightness level. This provides accurate quantitative results regarding the microstructure as the actual shape and size of the structures is not altered by any assumptions. Image analysis estimated two-dimensional parameters of the macro-porosity in virgin nuclear graphite grade. We have also explored the relative contribution of size and density of pores and cracks to the theoretical density of nuclear grade graphite. This characterization of isotropic fine-grained graphite will help in improving service life against neutron irradiation. 


\section{Materials}

\section{MATERIALS AND METHODS}

Virgin nuclear grade graphite samples were obtained in the form of cylinders and rectangular blocks.

\section{Sample preparation and optical microscopy}

Four different nuclear graphites of the same grade manufactured using different processes were considered in the present investigation. Sampling of suitable size was carried out by slow speed diamond saw. Grinding was done using Silicon Carbide (SiC) abrasive papers of grid size 240-320-400-600-800. Final polishing was performed with Alumina powder of size range $\sim 2$ and $\sim 0.5 \mu \mathrm{m}$. Samples were cleaned under deionised water. Final cleaning was executed in an ultrasonic bath containing acetone to remove all loosely adhered foreign substances to obtain scratch free mirror surface. Great care was taken while preparing the samples because graphite has a soft surface which was more prone to scratch, if not handled with care. The samples were examined in optical (Leica DM 3000) microscope at different magnifications. A minimum of five frames were considered to obtain a reliable statistical analysis. A prepared specimen for optical micrographs is shown in Figure1.

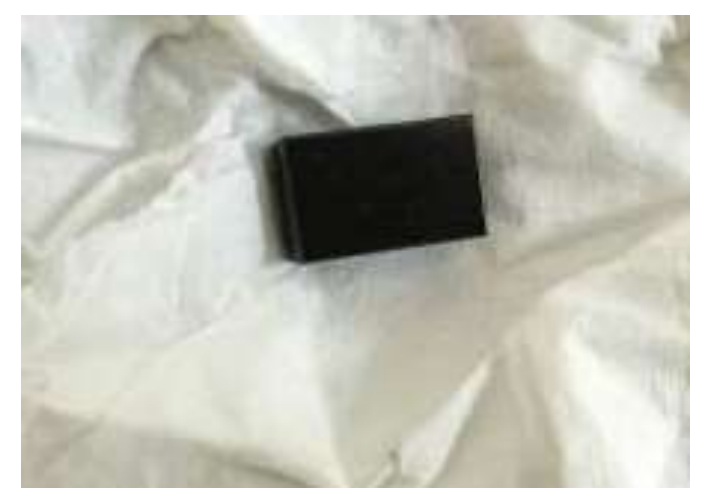

Figure 1. Test specimen for optical micrographs.

Three different phases were identified within the microstructure of polycrystalline nuclear graphite. The filler particles act as a phase. The second phase is the binder matrix within which the filler particle acts as an aggregate. Lastly, polycrystalline graphite also consisted of significant amounts of porosity. Optical images of the specimen at different magnification are shown in Figure 2. 


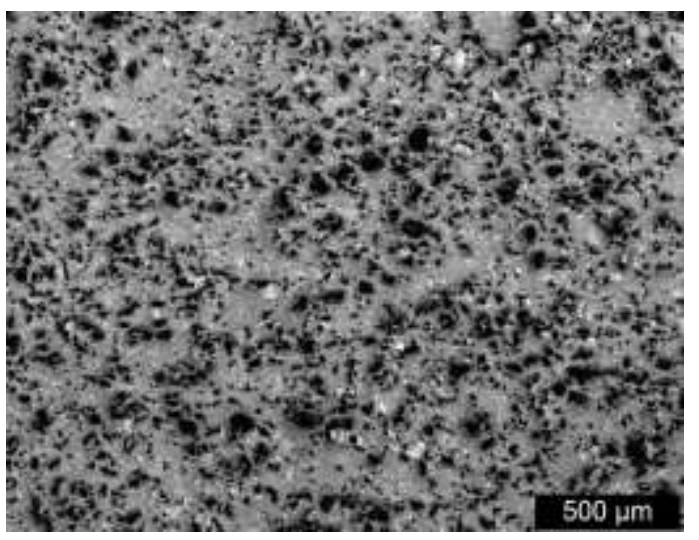

(a)

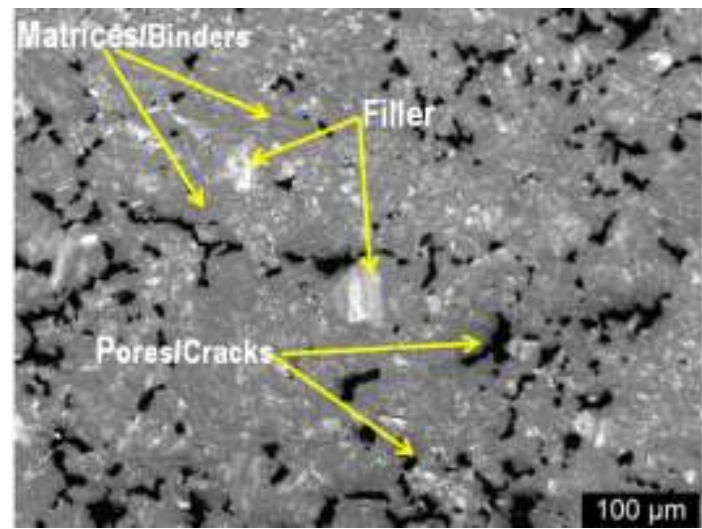

(c)

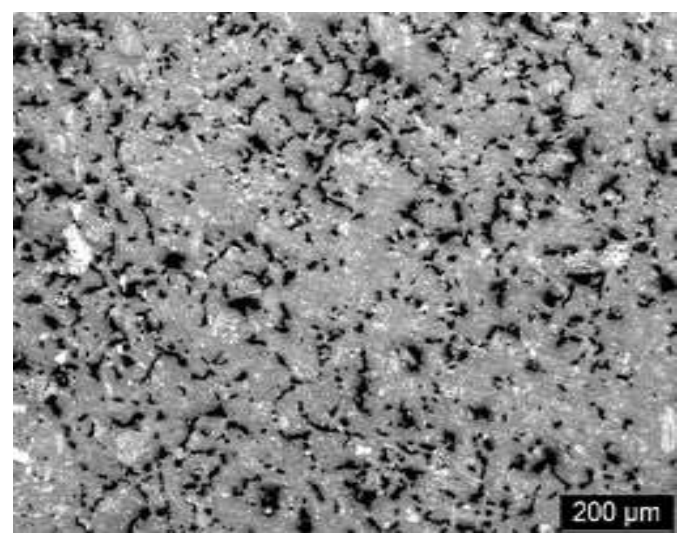

(b)

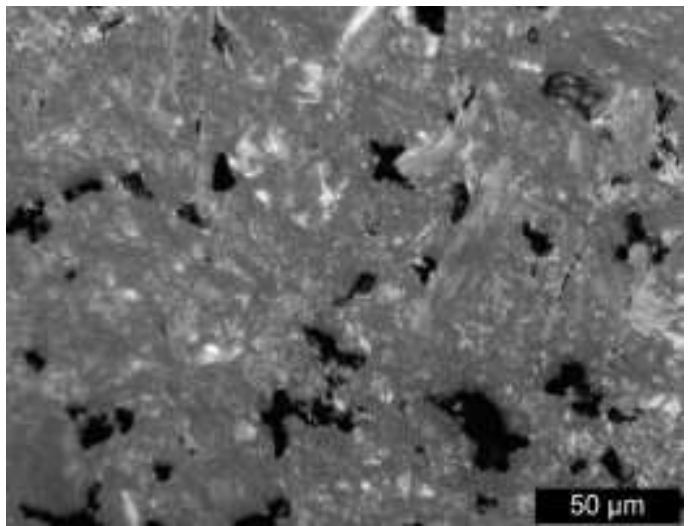

(d)

Figure 2. Optical micrographs of graphite sample at different magnification (a) 5X, (b) $10 \mathrm{X}$, (c) $50 \mathrm{X}$ and (d) $100 \mathrm{X}$

\section{Image analysis}

Quantification of microstructural features was done with image analysis software (Soft Imaging System Cell, Olympus Soft Imaging Solution $\mathrm{GmbH}$, and Version: Analysis Five) using images of the optical electron microscope. The gray-value optical image was acquired then following that the segmentation was done by dividing the image into separate regions. The simplest way of segmenting is through thresholding, separating the light and dark areas. The threshold was set on the basis of colour to distinguish between pore, filler, and binder. The deeply shaded black region was identified as pores and cracks, as shown in Figure 2. Quantitative data like area fraction of the pores and cracks, pore size distribution, were measured from this software. Optical micrograph and the same microstructure after threshold are shown in Figure 3. 


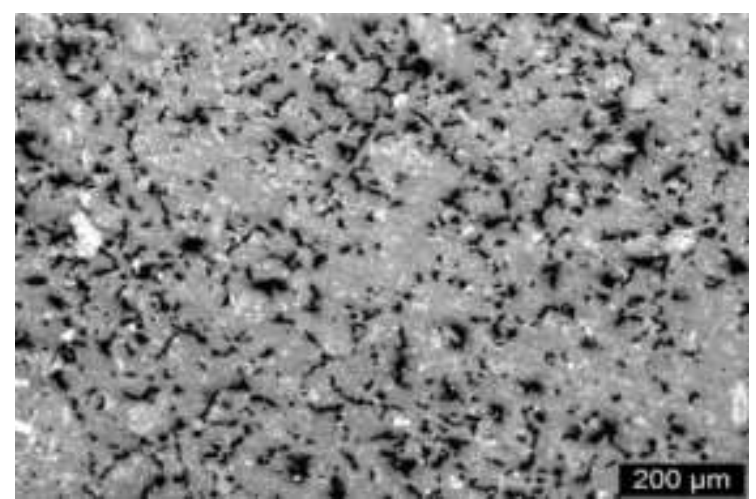

(a)

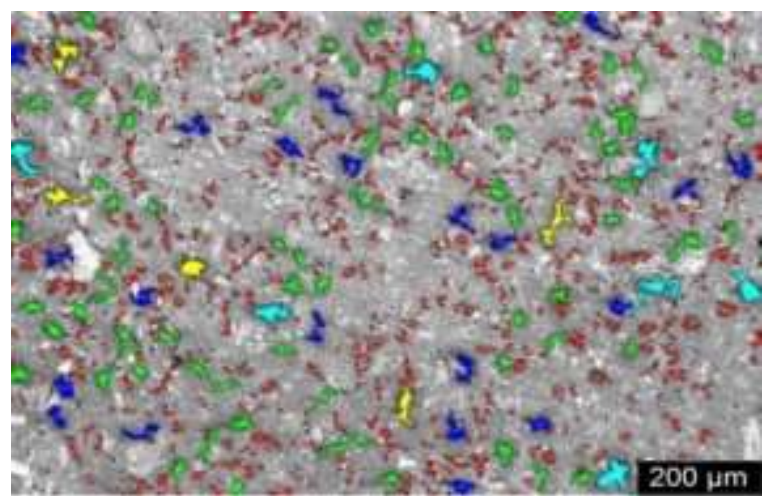

(b)

Figure 3. (a) Optical micrograph of nuclear graphite and (b) threshold image of optical micrograph

The threshold image shows the identified pores and cracks in different colours. The red, light blue, dark blue, yellow and green colours shows the pores and cracks of different size range. The ideal density of the graphite crystal is $2.26 \mathrm{~g} / \mathrm{cm}^{3}$ [25] but due to the presence of gas evolved pores, the calcination cracks and the micro cracks, the density of the nuclear graphite is generally lowered by $30-20 \%$. In this study, we have considered pores and the cracks seen in the optical microscopy to determine the density of the nuclear graphite samples. Density is calculated by using Equation (1) [26]:

$$
\varepsilon=(1-(\mathrm{d} \div 2.26)) \times 100
$$

where $\varepsilon=$ calculated porosity and cracks fraction percentage in the graphite samples and $\mathrm{d}=$ theoretical density of the graphite samples.

\section{RESULTS AND DISCUSSION}

The porosity in polycrystalline graphite can be categorized as open and closed porosity. Open porosity is theoretically accessible from the specimen surface. Closed porosity is not visible and exists as internal porosity at the crystal level. In image analysis, open porosity data were acquired. Image analysis was carried out from Optical images, to quantify macroporosity, i.e., gas evolved pores, and calcined cracks. Therefore, it is necessary to find them based on aspect ratio. In the present case if the aspect ratio is greater than 1.2 then they are considered as cracks and the rest of them are regarded as pores.

The data of image analysis was obtained in numerical form and are also presented through graphical distribution. Pores and cracks distribution/area fractions are numbered per $\mathrm{mm}^{2}$ and are represented through bar chart and shown in Figure 4. The investigated graphite samples are named as A, B, C, and D. 


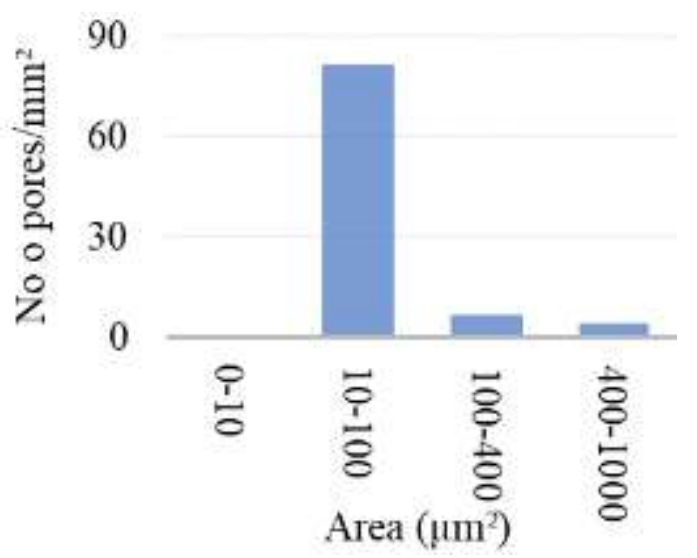

(a)

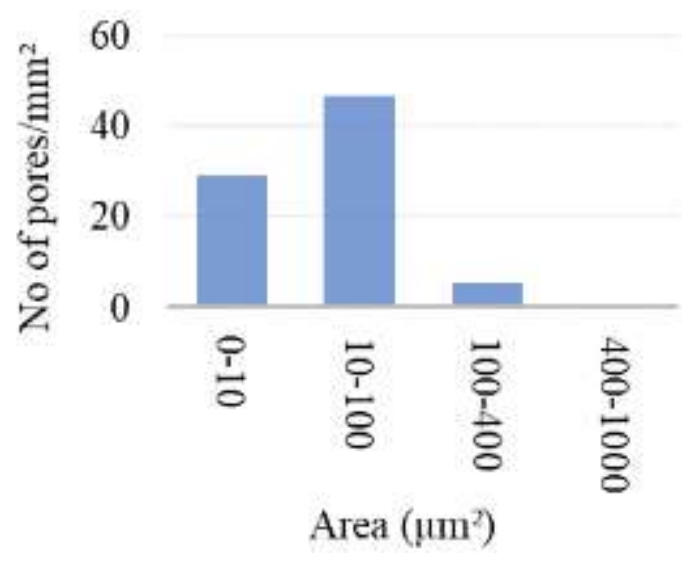

(c)

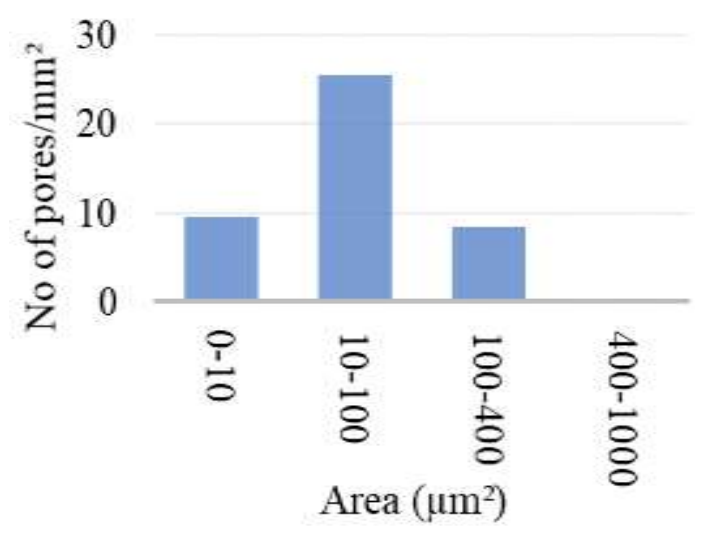

(e)

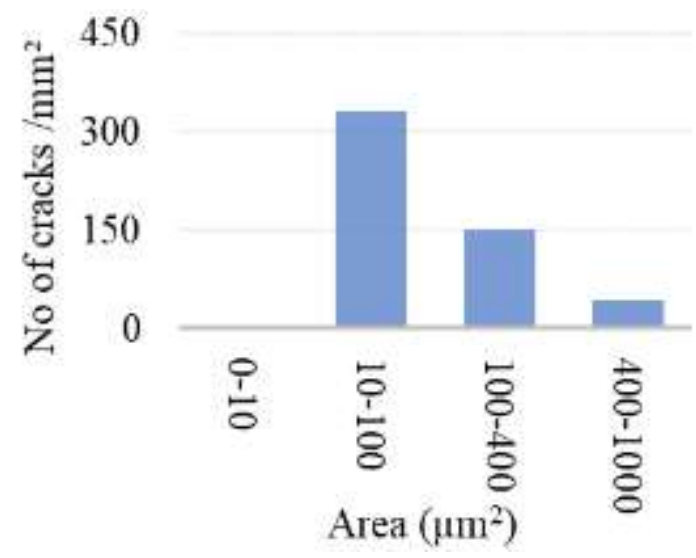

(b)

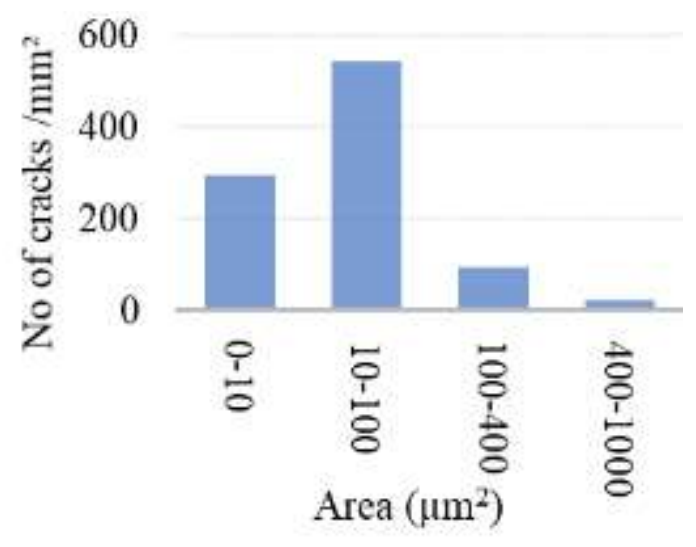

(d)

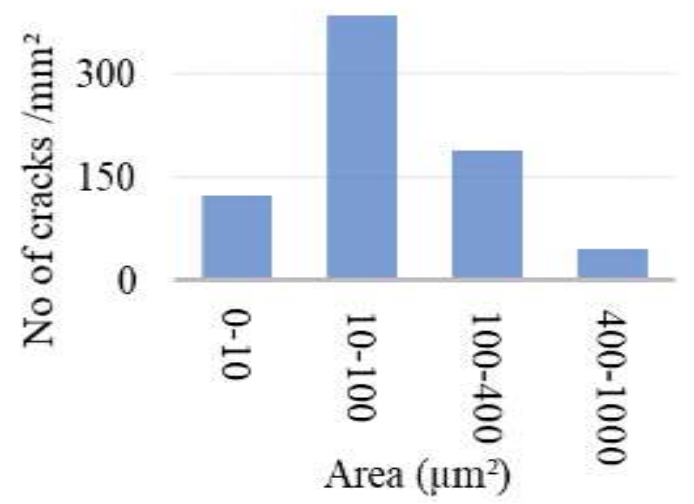

(f) 


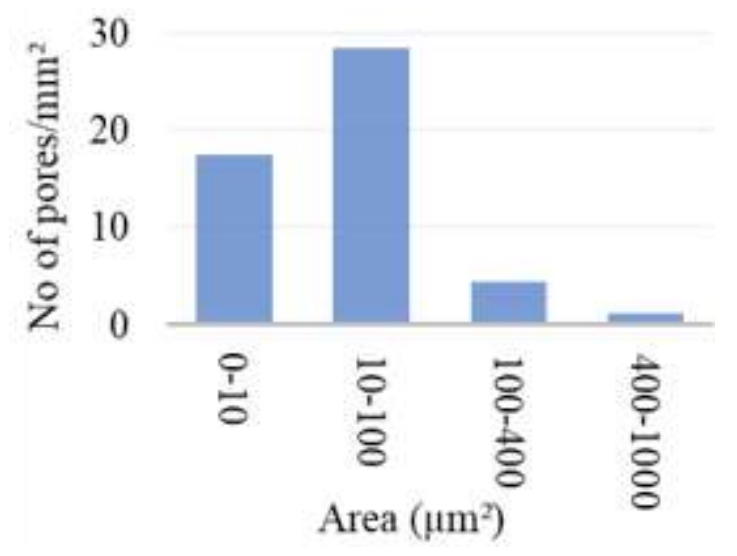

(g)

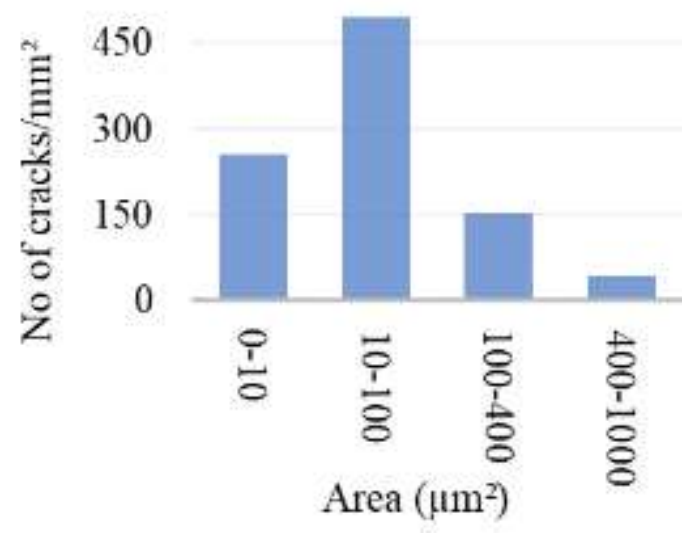

(h)

Figure 4. Numbers of pores and crack per $\mathrm{mm}^{2}$ (a-b) sample A, (c-d) sample B, (e-f) sample C and (g-h) sample D

The pore and crack size distribution are shown in Figure 4. The histograms show a range of large porosity and crack distribution in the investigated nuclear grade graphite samples. The largest and the smallest pores and cracks size range was found to be from $400-1000 \mu \mathrm{m}^{2}$ and $0-10 \mu \mathrm{m}^{2}$. Many of the pores and cracks were found in the range of $10-100 \mu \mathrm{m}^{2}$. Sample A has no pores in the size range of $0-10 \mu \mathrm{m}^{2}$, while in sample B and C pores of the size of 400$100 \mu \mathrm{m}^{2}$ were absent. The pores and cracks are uniformly distributed.

The pores and cracks area fraction were calculated by dividing the total pore and cracks area by the total area of the micrograph. For this computation to be valid, the porosity must be uniform throughout the graphite block. The statistical summary of the porosity analysis is shown in Table 1. It is inferred that sample A has the maximum porosity percentage and B the least. There appears is be more numbers of cracks in a unit area of $\mathrm{mm}^{2}$ in comparison to the number of pores. As most of the pores and cracks were found lying in the size range of $10-1000 \mu \mathrm{m}^{2}$, an increase in the area fraction of pores and cracks was compared with the pores and cracks density in the given area range. No connection was found between the two. Also, the changes in the number of pores and cracks in the size span of 400$1000 \mu \mathrm{m}^{2}$ showed no influence on the variation of the area fraction. Though sample B has the second highest count of the number of pores and cracks per $\mathrm{mm}^{2}$ but the pores + cracks area percentage is the lowest, which shows also that the numbers of pores, and cracks have no linear relationship with the porosity and crack area fraction. No clear picture was obtained about the elements contributing to the area fraction. 
Table 1. Porosity analysis of the nuclear grade graphite.

\begin{tabular}{cccc}
\hline Sample & Pores + cracks $(\%)$ & No of pores $/ \mathrm{mm}^{2}$ & No of crack $/ \mathrm{mm}^{2}$ \\
\hline A & 9.245 & 92.36 & 526.99 \\
B & 5.785 & 80.99 & 956.38 \\
C & 7.905 & 43.68 & 745.72 \\
D & 8.645 & 51.25 & 943.24 \\
\hline
\end{tabular}

Densities of all of the investigated samples have been calculated based on the ideal density of graphite crystal and \% porosity and cracks present in present samples. The derived average theoretical density of the graphite samples is collated in Table 2.

Table 2. Theoretical density of the investigated samples.

\begin{tabular}{cc}
\hline Sample & Theoretical density $\left(\mathrm{g} / \mathrm{cm}^{3}\right)$ \\
\hline A & 2.035 \\
B & 2.192 \\
C & 2.081 \\
D & 2.064 \\
\hline
\end{tabular}

The derived theoretical density of the samples was found in the range of $2.093 \pm 0.0686$. Sample A with the highest porosity and cracks percentage showed the lowest density, while sample B with the lowest pores and cracks area fraction has the highest density. Since, theoretical density is derived from the porosity and crack fraction, factors affecting the pores + cracks fraction also determine density. No direct correlation was found between pores and cracks density and their sizes with their area fraction.

\section{CONCLUSIONS}

Four different specimens of nuclear grade graphite were investigated in the present study. The microstructure of the specimens was examined in optical microscopes. An image analysis tool has been used to examine microstructures with different pores and cracks of different geometries. The investigation revealed the qualitative and quantitative information on pore distribution, characteristics of cracks. The theoretical density of the nuclear graphite samples were derived from the area fraction data. The theoretical density was found not to be controlled by pores and cracks density and their size directly. 


\section{REFERENCES}

[1] Zhou X, Tang Y, Lu Z, Zhang J, Liu B. Nuclear graphite for high temperature gascooled reactors. New Carbon Materials 2017;32:193-204.

[2] Marsden BJ. Nuclear graphite for high temperature reactors. Gas turbine power conversion systems for modular HTGRs.2001;46:177-92.

[3] Li Z, Chen D, Fu X, Miao W, Zhang Z. The influence of pores on irradiation property of selected nuclear graphites. Advances in Materials Science and Engineering 2012; 2012:1-7.

[4] Burchell TD, Snead LL. The effect of neutron irradiation damage on the properties of grade NBG-10 graphite.Journal of Nuclear Materials 2007;371:18-27.

[5] Burchell TD. Radiation effects in graphite.Comprehensive nuclear materials, Oxford: Elsevier 2012;299-324.

[6] Best JV, Stephen WJ, Wickham AJ.Radiolytic graphite oxidation.Progress in Nuclear Energy 1985;16:127-178.

[7] Brocklehurst JE, Brown RG, Gilchrist KE, Labaton VY.The effect of radiolytic oxidation on the physical properties of graphite. Journal of Nuclear Materials 1970;35:183-194.

[8] Wen K, Marrow J, Marsden B. Microcracks in nuclear graphite and highly oriented pyrolytic graphite (HOPG). Journal of Nuclear Materials 2008;381:199-203.

[9] Berre C,Mummery PM,Marsden BJ,Mori T,Withers PJ.Application of micromechanics model to the overall properties of heterogeneous graphite.Journal of Nuclear Materials 2008;381:124-128.

[10] Li Z,Chen D,Fu X,Miao W,Zhang Z.The influence of pores on irradiation property of selected nuclear graphites. Advances in Materials Science and Engineer 2012;2012:1-7.

[11] Berre C, Fok SL, Mummery PM, Ali J, Marsden BJ, Marrow TJ, Neighbour GB. Failure analysis of the effects of porosity in thermally oxidized nuclear graphite using finite element modeling. Journal of Nuclear Materials 2008;381:1-8.

[12] Babout L,Marsden BJ,Mummery PM,Marrow TJ.Three-dimensional characterization and thermal property modelling of thermally oxidized nuclear graphite. Acta Materialia 2008;56:4242-4254.

[13] Berre C, Fok SL, Marsden BJ, Babout L, Hodgkins A, Marrow TJ, Mummery PM. Numerical modelling of the effects of porosity changes on the mechanical properties of nuclear graphite.Journal of Nuclear Materials 2006;352:1-5.

[14] Eto M, Oku T, Konishi T. High temperature Young's modulus of a fine-grained nuclear graphite oxidised or prestressed to various levels. Carbon.1991; 29:11-21.

[15] Mao ZQ, Zhang C, Xiao L. A NMR-based porosity calculation method for low porosity and low permeability gas reservoir.Oil Geophysics. Prospect 2010;45:105109.

[16] Zauer M, Pfriem A, Wagenfuhr A. Toward improved understanding of the cell wall density and porosity of wood determined by gas pycnometry.Wood Science Technology 2013; 47:1197-1211.

[17] Sing K. Adsorption methods for the characterisation of porous materials. Advances in Colloid and Interface Science 1998;76-77:3-11. 
[18] Burchell TD. A microstructure-based fracture model for polygranular graphite. Carbon 1996;34:297-316.

[19] Martin WD, Putman BJ, Kaye NB.Using image analysis to measure the porosity distribution of a porous pavement.Construction and Building Materials 2013;48:210217.

[20] Hodgkins A, Marrow TJ, Mummery P, Marsden B, Fok A. X-Ray tomography observation of crack propagation in nuclear graphite. Material Science and Technology 2006; 22:151-1045.

[21] Babout L, Marrow TJ, Mummery PM, Withers PJ. Mapping the evolution of density in 3D of thermally oxidized graphite for nuclear applications.Scripta Materialia 2006;54: 829 .

[22] Jones AN, Hall GN, Joyce M, Hodgkins A, Wen K, Marrow TJ. Microstructural characterisation of nuclear grade graphite. Journal of Nuclear materials 2008; 381:152-7.

[23] Wen KY, Marrow TJ, Marsden BJ. The microstructure of nuclear graphite binders. Carbon 2007; 46:62-71.

[24] Kane J, Karthik C, Butt DP, Windes WE, Ubic R. Microstructural characterization and pore structure analysis of nuclear graphite. Journal of Nuclear Materials 2011; 415:189-197.

[25] Wen K, Marrow J, Marsden B. Microcracks in nuclear graphite and highly oriented pyrolytic graphite (HOPG). Journal of Nuclear Materials 2008;381:199-203.

[26] Chi SH, Kim GC. Comparison of $3 \mathrm{MeV}$ C+ion-irradiation effects between the nuclear graphites made of pitch and petroleum cokes.Journal of Nuclear Materials 2008;381:98-105. 